\title{
ANALYSIS OF RADAR AND OPTICAL SPACE BORNE DATA FOR LARGE SCALE TOPOGRAPHICAL MAPPING
}

\author{
W. Tampubolon *, W. Reinhardt \\ AGIS, Institute for Applied Computer Science, Universität der Bundeswehr München, Germany - (winhard.tampubolon, \\ wolfgang.reinhardt)@unibw.de
}

Commission VI, WG VI/4

KEY WORDS: stereo, GCP, accuracy, topography, orthorectification, radargrammetry

\begin{abstract}
:
Normally, in order to provide high resolution 3 Dimension (3D) geospatial data, large scale topographical mapping needs input from conventional airborne campaigns which are in Indonesia bureaucratically complicated especially during legal administration procedures i.e. security clearance from military/defense ministry. This often causes additional time delays besides technical constraints such as weather and limited aircraft availability for airborne campaigns. Of course the geospatial data quality is an important issue for many applications. The increasing demand of geospatial data nowadays consequently requires high resolution datasets as well as a sufficient level of accuracy. Therefore an integration of different technologies is required in many cases to gain the expected result especially in the context of disaster preparedness and emergency response. Another important issue in this context is the fast delivery of relevant data which is expressed by the term "Rapid Mapping".

In this paper we present first results of an on-going research to integrate different data sources like space borne radar and optical platforms. Initially the orthorectification of Very High Resolution Satellite (VHRS) imagery i.e. SPOT-6 has been done as a continuous process to the DEM generation using TerraSAR-X/TanDEM-X data. The role of Ground Control Points (GCPs) from GNSS surveys is mandatory in order to fulfil geometrical accuracy. In addition, this research aims on providing suitable processing algorithm of space borne data for large scale topographical mapping as described in section 3.2.

Recently, radar space borne data has been used for the medium scale topographical mapping e.g. for 1:50.000 map scale in Indonesian territories. The goal of this on-going research is to increase the accuracy of remote sensing data by different activities, e.g. the integration of different data sources (optical and radar) or the usage of the GCPs in both, the optical and the radar satellite data processing. Finally this results will be used in the future as a reference for further geospatial data acquisitions to support topographical mapping in even larger scales up to the 1:10.000 map scale.
\end{abstract}

\section{INTRODUCTION}

Since 2000, the International Charter on Space and Major Disaster has established an agreement by coordinating the involved agencies all around the globe to initialize an effective system collaboration of space data acquisition for providing remote sensing data within affected regions during disaster situations. Initiated by the French Space Agency (CNES) and the European Space Agency (ESA), the members of that charter now are 23 institutions either from private or governmental sector providing widely used space borne remote sensing data for disaster preparedness and emergency response. Under this charter, the provided space borne imagery data shall be distributed by the participating agencies on a voluntary basis without any direct funding and payment during the period of natural or man-made disasters in any part of the globe. This important breakthrough has triggered awareness of the other potential institutions to participate in a mutual cooperation. The most prominent instance was activated at the end of 2004 when earthquakes followed by a tsunami have hit the Indian Ocean region. At that time, the high resolution imageries were freely given to the public through authorized users immediately.

\subsection{Research Background}

Geospatial information nowadays has turned into a primary need in human lives. This characteristic leads to a massive development of geospatial industries in parallel with the invention of new technologies in an open and attractive worldwide market. Heavy competition from different platforms, sensors, and techniques is coming up as a logical result of geospatial demand explosion around the globe.

Under the recent Act.Nr.4/yr.2011 about Geospatial Information in Indonesia, the Geospatial Information Agency of Indonesia (BIG) must take responsibility to provide official topographic map data which shall cover 1.9 million square kilometers land area of Indonesia which is approx. 4 times the land area of Germany.

This monumental governmental legislation was really an opportunity and a challenge for the geospatial data development especially to support the economic development in Indonesia. In that case, the proper technologies and methodologies have to be integrated to speed up the huge topographic mapping program in various map scales specifically for large scale mapping i.e. equal or larger than 1:10.000. 
As an example for the 1:10.000 map scale, the number of single map sheets in a 4.6 by $4.6 \mathrm{~km}$ to be produced are 91.547 (Table 1). Giving $10 \%$ priority for cities or built areas, it will end up in 9.155 map sheets. A normal capacity for the annual production of the 1:10.000 map scale is 100-200 map sheets. It means without any acceleration activity as a breakthrough, the 1:10.000 topographic maps of Indonesia will be once completed in $46-92$ years.

Moreover as one of the vulnerable countries around a disaster prone area - sometimes called ring of fire - Indonesia really needs sophisticated seamless topographical map data for better disaster preparedness and quick emergency response. Topographical maps are essential because they contain basic geospatial features including earth surface terrain information with respect to its proper geometrical accuracies.

\begin{tabular}{|r|r|c|r|r|}
\hline & $\begin{array}{c}\text { Map scale } \\
(1: \mathrm{M})\end{array}$ & $\begin{array}{c}\text { Map Coverage } \\
\text { (Length } \times \text { Width) } \\
\text { in Km }\end{array}$ & $\begin{array}{c}\text { Map Sheets } \\
\text { (Numbers) }\end{array}$ & $\begin{array}{c}\text { Availibility } \\
\text { (\%) }\end{array}$ \\
\hline 1 & $1,000,000$ & $668 \times 442$ & 37 & 0 \\
2 & 500,000 & $334 \times 221$ & 103 & 0 \\
3 & 250,000 & $167 \times 111$ & 309 & 100 \\
4 & 100,000 & $55.6 \times 55.6$ & 1,245 & 0 \\
5 & 50,000 & $27.8 \times 27.8$ & 3,899 & 62 \\
6 & 25,000 & $13.8 \times 13.8$ & 13,020 & 14 \\
$\mathbf{7}$ & $\mathbf{1 0 , 0 0 0}$ & $\mathbf{4 . 6} \times \mathbf{4 . 6}$ & $\mathbf{9 1 , 5 4 7}$ & $\mathbf{0 . 7}$ \\
8 & 5,000 & $2.3 \times 2.3$ & 379,014 & 0.06 \\
9 & 2,500 & $1.15 \times 1.15$ & 880,206 & 0 \\
10 & 1,000 & $0.58 \times 0.58$ & $2,729,319$ & 0 \\
\hline
\end{tabular}

Table 1. Indonesian Topographical Maps Volume

Utilization of geospatial enabled data using topographic map as a basic reference is mandatory in order to provide accurate quick emergency response, often called rapid mapping. This critical aspect triggers worldwide cooperation under Services and Applications for Emergency Response (SAFER) projects (Schneiderhan, 2010), in which the utilization of space borne based data including VHRS imagery data, will be really initiated immediately in the period of major disasters around the globe.

During disaster and emergency situations, geospatial data can provide important information for decision support system. As one instance of basic geospatial data, large scale topographical maps are essential in order to enable accurate analysis within quite a number of societal challenges. The advancement of geospatial data as an important part of governmental activities has been in focus since 2011 by the advent of a legislation about Geospatial Information in Indonesia. Large scale topographical mapping has been put on high priority to support the nationwide development e.g. related to disaster preparedness, detail spatial planning, etc.

The massive development of space remote sensing technologies enhances both spatial and spectral resolution to enable geospatial data production in order to provide the high end Indonesian Spatial Data Infrastructure (Ina-SDI). The advantage of this space segment is the cut-off of bureaucratic problems during the security clearance procedure.

In this context, heavy competition in terms of geospatial data source provision is really an issue now especially in the recent years while aerial data acquisition progresses were stagnant due to its high costs. Looking closer at this opportunity, it will be an advantage if the integration between space borne and alternative technologies can support each other to accelerate topographical map production.

After the successful launch of the next complementary generation of German TerraSAR-X-add-on Digital Elevation Measurement (TanDEM-X) satellite in 2010, this ambitious project will hopefully provide worldwide DEM in a resolution of $10 \mathrm{~m}$ in much similar way as the SRTM global Digital Elevation Model (DEM) provision in 2001. The development of TanDEM-X platform with a bi-static interferometry (Breit, 2012) aims on providing HRTI-3 global DEM which has the accuracy within $10 \mathrm{~m}$ absolute horizontal (circular error) and 10 m absolute vertical (linear error) at $90 \%$ level of confidence.

The major advantages of using satellite-based radar data are the relatively weather independence and free security clearance procedure. However, using radar data for large scale topographical mapping is still constrained especially for object interpretation and geometric accuracy matter. In order to overcome these drawbacks, the integration between radar and optical sensor imageries is assumed as a potential solution.

Some recently upcoming alternative space borne technologies for geospatial data production give a high resolution approach to the generation of orthoimages and digital elevation models (DEM). In order to guarantee the planimetric and height accuracy, space borne data processing must be supported by ground segment data i.e. Ground Control Points (GCP) which refers to the national geodetic and geodynamic reference network.

Bridging the distance from those two kinds of sensors will be created by establishing a data processing chain in rapid mapping where the quick response and high accuracy can be achieved simultaneously. This data integration research aims to integrate radar and optical data by incorporating GCP from Global Navigation Satellite System (GNSS) measurements. Finally, it will provide geospatial datasets with proper geometric accuracy to be used as a reference.

Reference data and GCPs are always an issue with regards to the geometric accuracy of VHRS imagery data (Tampubolon, 2012) and hence it will directly increase the project costs. Therefore, synchronized GCP measurements can presumably increase project efficiency without reducing geometric accuracy.

\subsection{Research objectives and motivation}

The main objective of this research is to provide an integration of optical and radar space borne data processing in the context of large scale topographical mapping. By comparing DEM data generated from different processing scheme, the standard procedure of satellite-based data processing can be improved with the optimized solution.

With respect to other geospatial data projects i.e. orthorectified Very High Resolution Satellite (VHRS) imagery, the DEM generation process can be improved in order to increase the resolution and accuracy of the output. By using GCPs data as an important input, the planimetric and elevation accuracy shall be improved in order to comply with the large scale topographical mapping requirements. Therefore this paper demonstrates a project synergy in order to achieve optimum geometric accuracy with minimum redundancy measures. 
Another goal of this paper is to give recommendations for a proper usage of space borne data for an improved data processing chain in the special case of Indonesia. It includes the GCP requirements as well as the processing schemes based on certain assessment standards in the context of large scale topographical mapping in Indonesia.

\subsection{Workflow}

This paper mainly concentrates on the geometric accuracy of orthoimages and DEMs. In order to verify and identify the geometric accuracy, it is necessary to use valid and independent geospatial data source and techniques with certain quality.

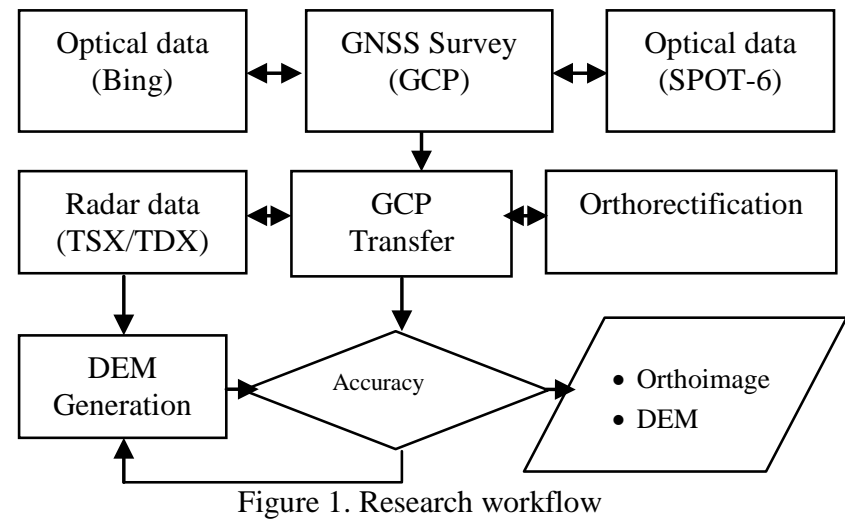

Basically there are 3 aspects to be evaluated for this satellite data processing namely sensor, algorithm and GCP (Figure 1). Finally this research aims its way to provide both radar and optical space borne data in a proper geometric accuracy for large scale topographical mapping purpose.

\subsection{Area of Interest}

The test area "Bandung" has been selected based on the terrain complexity and the data availability, including geodetic reference network infrastructure. In general, the test site covers approximately an area of $60 \times 60 \mathrm{~km}$. As a pre-defined constraint, the terrain condition of the study site is classified as undulated with a lot of hilly or mountainous regions (Figure 2).

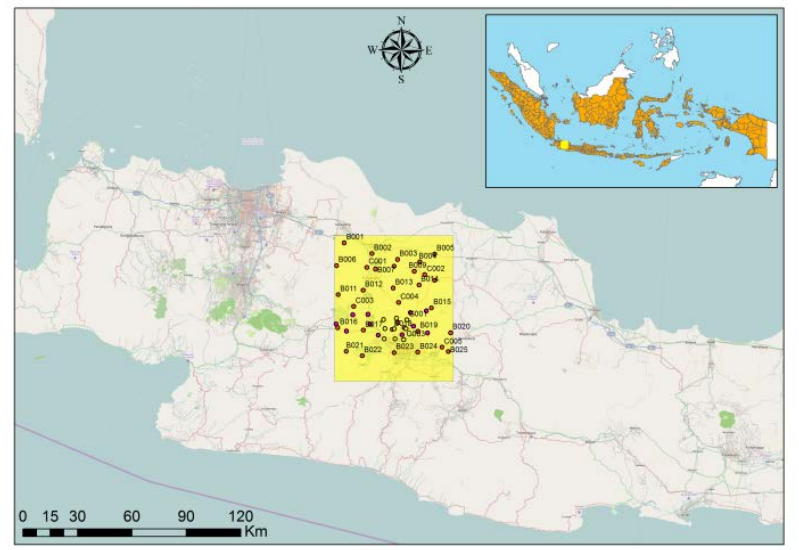

Figure 2. Test area (Bandung, Indonesia)

In the development context, it is prioritized by the stakeholders to accomplish the detail spatial planning over that national strategic area. Therefore in 2012, an airborne data acquisition using medium format digital metric camera has been done in order to produce the topographical map of the area in a scale of 1:5,000. This data has been used as a reliable reference data for accuracy assessment in section 4.1.

Nevertheless, for large scale mapping purpose, the detail investigation focuses on 1 map sheet of 1:5.000 (1209-3136D) with a size approximately $2.3 \times 2.3 \mathrm{~km}$ on the ground. Detail AOI has been selected under the assumption that the topographical features has not totally changed yet. Therefore it makes sense to use GCPs data from different time series for data production and validation.

\section{DATA SOURCES}

\subsection{Space borne data}

The optical space borne data used in this paper is pan-sharpened SPOT 6 with a resolution of $1.5 \mathrm{~m}$. To enable the detail investigation on geometric accuracy aspect, there are 2 type of processing level which shall be compared. Primary standard product is used for in-house orthorectification by using GCPs and DEM data while Standard Ortho product has been geometrically processed by encountering viewing angle and ground effects.

In parallel, radar space borne data has a role for above mentioned orthorectification purpose. On the other hand, topographical mapping requires DEM as an input for creating terrain information including contour lines and other hypsographic components.

\begin{tabular}{|c|c|c|c|c|}
\hline Product & $\begin{array}{c}\text { Post } \\
\text { spacing } \\
\text { (arc-sec) }\end{array}$ & $\begin{array}{c}\text { Post } \\
\text { spacing } \\
\text { (m) }\end{array}$ & $\begin{array}{c}\text { Rows/columns } \\
\text { (1x1 }{ }^{\circ} \text { tile) }\end{array}$ & $\begin{array}{l}\text { File size } \\
\text { (MB) }\end{array}$ \\
\hline DTED Level 0 & 30 arc-sec & $\begin{array}{c}\text { approx. } \\
1,000\end{array}$ & $121 / 121$ & .03 \\
\hline $\begin{array}{lll}\text { DTED Level } & 1 \\
\text { and DEM } 1^{\circ} & \end{array}$ & 3 arc-sec & $\begin{array}{l}\text { approx. } \\
100\end{array}$ & $1201 / 1201$ & 2.8 \\
\hline DTED Level 2 & 1 arc-sec & approx. 30 & $3601 / 3601$ & 24.7 \\
\hline DEM 7.5' & -- & true 30 & $\begin{array}{c}\text { (in } 7.5 \text { minute } \\
\text { tiles) }\end{array}$ & \\
\hline HRTI Level 3 & $\begin{array}{l}0.4 \text { arc- } \\
\text { sec }\end{array}$ & approx. 12 & $9001 / 9001$ & 309 \\
\hline HRTI Level 4 & $\begin{array}{c}0.2 \text { arc- } \\
\text { sec }\end{array}$ & approx. 6 & $18001 / 18001$ & 1236 \\
\hline HRTI Level 5 & $\begin{array}{l}0.04 \text { arc- } \\
\text { sec }\end{array}$ & approx. 1 & $90001 / 90001$ & 30,900 \\
\hline
\end{tabular}

Table 2. NGA/NIMA and USGS Digital Elevation Data specifications (USGS, 1993 \& DLR, 2013)

HRTI stands for High Resolution Terrain Information, while DTED stands for Digital Terrain Elevation Data (Table 2). In order to get better accuracy, HRTI will be stored as 4-byte (32bit) in a case that elevations can be stored in real numbers instead of integers. However, this will also double the file size compared to using 16-bit data. Currently HRTI can usually be collected using an airborne IFSAR (Interferometric Synthetic Aperture Radar) platform.

Intermediate DEM (IDEM) released by TanDEM-X scientific service in 2014 has found its way to comply with the HRTI Level 3 specifications (DLR, 2013). While using interferometric approach in the DEM generation, the height calibration still relies on the GCP from Ice, Cloud and Land Elevation Satellite (ICESat) though. This scientific data has been used to verify the DEM generation process using radargrammetric approach. 
In addition, TSX/TDX detected products i.e. Multi-look Ground-range Detected-Spatially Enhanced-Spatially Enhanced (MGD-SE) data have been used as a raw data to proceed with DEM generation using radargrammetric approach (Table 3).

\begin{tabular}{|c|c|c|}
\hline Scenes & Looking Direction & Acquisition Date \\
\hline S01 & Descending & 20 March 2012 \\
\hline S02 & Descending & 05 August 2012 \\
\hline S03 & Descending & 07 September 2012 \\
\hline S04 & Ascending & 28 July 2012 \\
\hline S05 & Ascending & 22 August 2011 \\
\hline S06 & Ascending & 16 August 2011 \\
\hline S07 & Ascending & 27 August 2011 \\
\hline
\end{tabular}

Table 3. TerraSAR-X(TSX) / TanDEM-X(TDX) Data

\subsection{Reference Frame}

There are two types of fundamental geospatial data which shall be considered as a reference for thematic or general spatial purposes. The first component is the topographical map itself which will be provided in the Indonesian Spatial Data Infrastructure (Ina-SDI). This type of reference frame must be used as the official reference for both the content and positional (geometrical) aspect.

Secondly is the geodetic and geodynamic control network which can be considered as Indonesian geospatial reference frame (SRGI). As a main core component, this official network mainly establishes reference stations serving different kind of users including topographical map producers. The question about availability is always raised regarding to the reference control network (Figure 3).

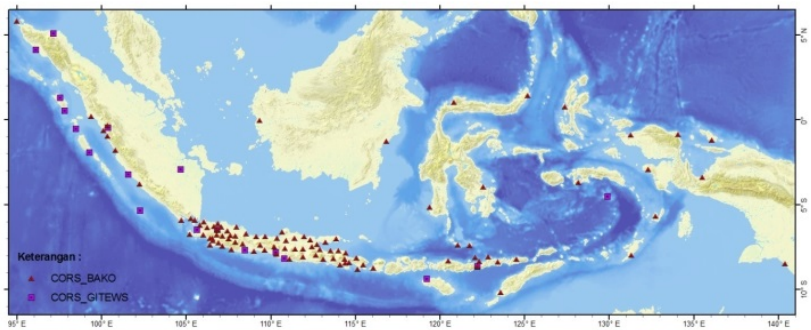

Figure 3. Continuously Operating Reference Stations (CORS) of Indonesia (courtesy of BIG)

Those basic geospatial data determine overall geospatial accuracy in order to support "One Map" policy in Indonesia. This policy restricts any thematic geospatial users to refer on fundamental geospatial datasets e.g. topographic map, coastal map and bathymetric map.

\section{DATA PROCESSING}

This paper describes remote sensing data processing by getting an advantage of GCP from GNSS measurements and stereo optical compilation. It is concentrated on the data processing performance in order to obtain sufficient geospatial data sources for large scale topographical mapping.

\subsection{GNSS data}

GNSS survey is conducted for providing the GCPs data with a proper spatial distribution over the test area. In principal, GCP measurements cover two main purposes of the data processing. The first one is to check the quality of the orthorectified imagery and the latter one is to establish accurate GCPs network for both ortorectification and DEM generation.

GCPs have been selected in the field by defining point-based objects which can be identified clearly in the SPOT-6 data with high certainty. The point selection has to be done by extracting point objects from regular form features within the minimum size of 2 times image resolution i.e. $3 \mathrm{~m}$. Suitable examples of this regular form features are the building edge, tennis field and the round objects (Figure 4).

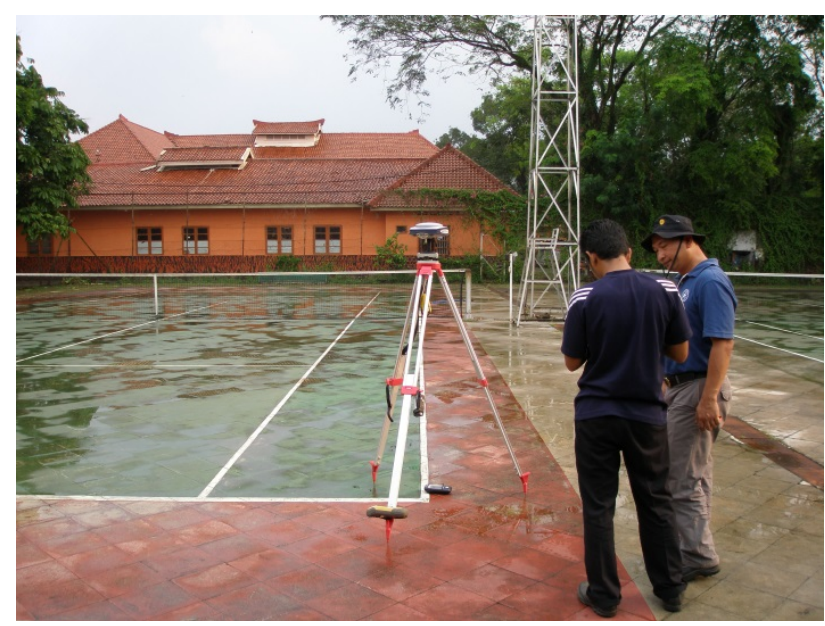

Figure 4. GNSS Survey

In the context of the GCP dataset provisions, there are 4 possible options have been implemented for GNSS data processing:

\section{Near Fix Reference}

GPS measurement refers to the nearest available CORS operated by BIG which is located in Lembang, around $14 \mathrm{~km}$ in the centre part of the AOI. This CORS can deliver GPS raw data in the highest resolution i.e. up to 1 second interval time.

2. Precise Point Positioning (PPP)

PPP is an online application for GNSS data post-processing that allows users to submit raw GPS data via internet and receive data with enhanced positioning precisions within a global reference frame, based on precise GNSS Orbit and Clock information,.

3. Absolute Positioning

The measurement is performed independently without any reference station consideration.

4. Far Fix Reference

GNSS measurements refer to the CORS operated by BIG which is located in BIG office (BAKO), around $160 \mathrm{~km}$ from the AOI.

GNSS measurement schemes can lead to the proper field data collection and processing methodology with respect to the accuracy requirement. Optimizing between accuracy and productivity aspects, PPP proves an independent measurement with sub meter accuracy despite of reference network availability.

\begin{tabular}{|l|c|c|c|c|}
\hline GCP_ID & $\begin{array}{c}\text { Near Fix } \\
\text { Reference } \\
(\mathrm{m})\end{array}$ & $\begin{array}{c}\text { PPP } \\
(\mathrm{m})\end{array}$ & $\begin{array}{c}\text { Absolute } \\
(\mathrm{m})\end{array}$ & $\begin{array}{c}\text { Far Fix } \\
\text { Reference } \\
(\mathrm{m})\end{array}$ \\
\hline BDG1 & 0.043 & 0.542 & 7.564 & 5.543 \\
\hline BDG2 & 0.024 & 0.042 & 6.323 & 3.432 \\
\hline BDG3 & 0.054 & 0.342 & 5.321 & 4.134 \\
\hline BDG4 & 0.053 & 0.031 & 4.745 & 3.571 \\
\hline
\end{tabular}




\begin{tabular}{|l|r|r|r|r|}
\hline BDG5 & 0.041 & 0.437 & 8.560 & 10.049 \\
\hline BDG6 & 0.032 & 0.104 & 1.678 & 5.067 \\
\hline BDG7 & 0.037 & 0.507 & 9.034 & 7.240 \\
\hline BDG8 & 0.015 & 0.023 & 7.283 & 1.650 \\
\hline BDG9 & 0.077 & 0.422 & 4.548 & 3.423 \\
\hline Acc. & $\mathbf{0 . 0 6 9}$ & $\mathbf{0 . 5 2 1}$ & $\mathbf{8 . 7 5 5}$ & $\mathbf{1 0 . 2 7 9}$ \\
\hline
\end{tabular}

Table 4. GNSS measurements accuracy

For this research, there are 33 GCPs which have been measured using geodetic GPS double frequency L1/L2 (Figure 5). Implementing rapid static differential positioning, every GCP has been measured not less than 30 minutes in order to get sub centimeter accuracy.

The GNSS measurements collected either by using rapid static or Continuous Operating Reference System (CORS) in real time kinematic mode have been selected in order to increase geometric accuracy. Subsequently it is necessary to verify the results through different GNSS measurement schemes. For this purpose, GNSS measurements using Precise Point Positioning (PPP) were conducted.

In addition to the rapid static measurements, some more points i.e. 9 Independent Check Points (ICP) have been measured utilizing Continuous Operating Reference System (CORS) service for elevation accuracy assessment purpose (Table 4).

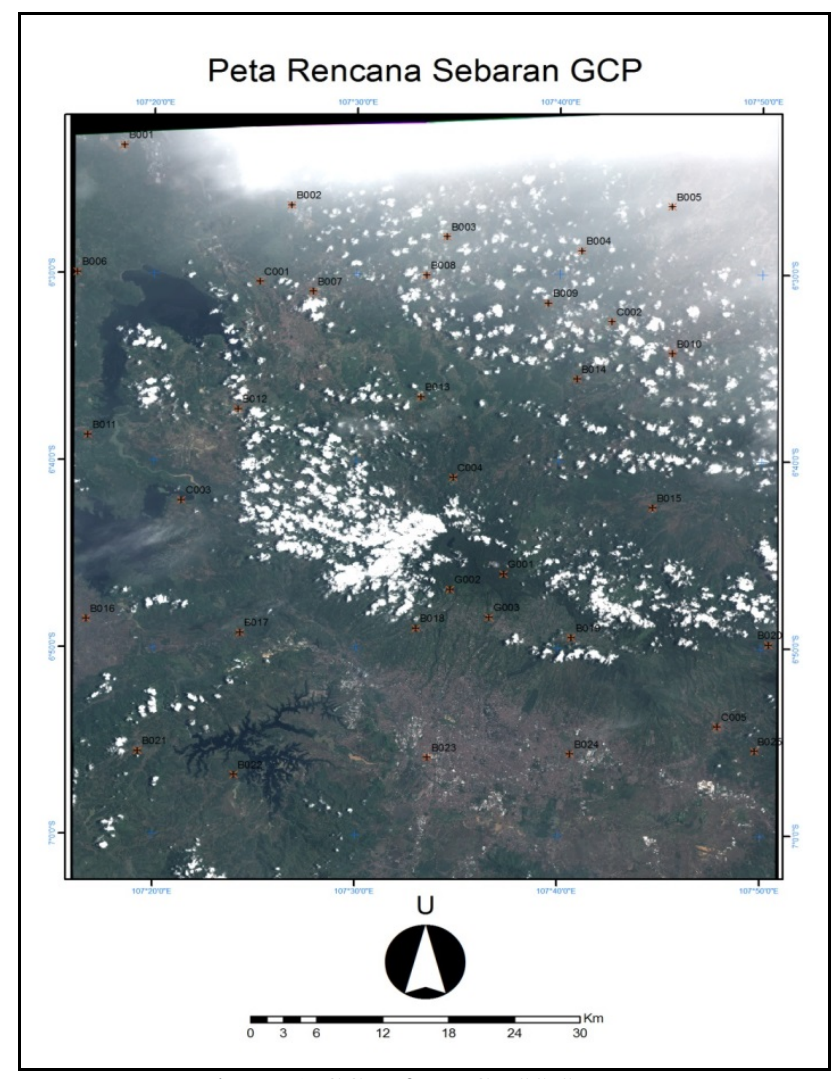

Figure 5. GCPs from GNSS Survey

\subsection{Orthorectification and DEM generation}

The purpose of this research is mainly to analyse the national orthorectification program in particular for the provision of large scale topographical maps, in which the expected SPOT-6 data shall fulfil $5 \mathrm{~m}$ horizontal accuracy. For this investigation, SPOT 6 data in $1.5 \mathrm{~m}$ Ground Sampling Distance (GSD) has been combined with TerraSAR-X/TanDEM-X data by getting an input from GCPs data.

It has also been investigated how services provided in the context of the Services and Applications for Emergency Response (SAFER) project can be used to produce virtual GCPs from reference image, which leaded to useful results. In this context, the integration of optical (SPOT 6) and radar (TanDEM-X) data for large scale topographical mapping has been implemented for the Digital Elevation Model (DEM) generation process.

Hybrid orthorectification has been selected as a mathematical solution to reconstruct remote sensing data including VHRS imagery by combining planimetric and terrain aspect of earth surface. Applying the collinearity approach to the optical data leads to:

$$
\begin{aligned}
& x=x_{0}-\mathrm{f} \frac{a_{1}\left(X-X_{g}\right)+b_{1}\left(Y-Y_{g}\right)+c_{1}\left(Z-Z_{g}\right)}{a_{g}\left(X-X_{g}\right)+b_{g}\left(Y-Y_{g}\right)+c_{g}\left(Z-Z_{g}\right)} \\
& y=y_{0}-\mathrm{f} \frac{a_{2}\left(X-X_{g}\right)+b_{2}\left(Y-Y_{g}\right)+c_{2}\left(Z-Z_{g}\right)}{a_{g}\left(X-X_{g}\right)+b_{g}\left(Y-Y_{g}\right)+c_{g}\left(Z-Z_{g}\right)}
\end{aligned}
$$

where $(X, Y, Z)$ are the object ground coordinates, $\left(X_{s}, Y_{s}, Z_{s}\right)$ are the sensor projection center coordinates, $\left(\mathrm{x}_{0}, \mathrm{y}_{0}\right)$ are the coordinates of principal point, $(\mathrm{x}, \mathrm{y})$ are the image coordinates, and $f$ is the focal length of the sensor. The nine parameters those have to be calculated are $\mathrm{a}_{1}, \mathrm{a}_{2}, \mathrm{a}_{3}, \mathrm{~b}_{1}, \mathrm{~b}_{2}, \mathrm{~b}_{3}, \mathrm{c}_{1}, \mathrm{c}_{2}, \mathrm{c}_{3}$.

As depicted in Figure 6, the GCPs have been selected from optical dataset into radar dataset based on feature extraction from Ortho Rectified Imagery (ORI). At the first place, orthorectified SPOT-6 data with planimetric accuracy in $4.7 \mathrm{~m}$ has been used as the reference image for first initial orthorectification of radar data. Certainly it requires elevation data in which it can be extracted from radar space borne data (TerraSAR-X).

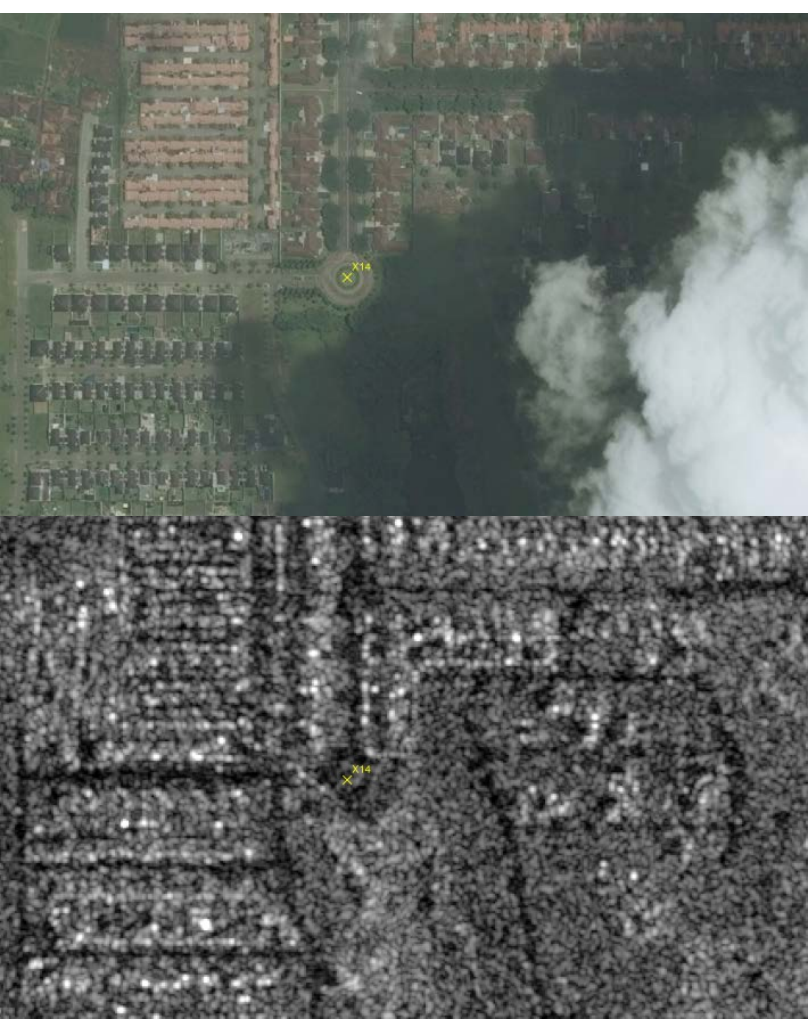

Figure 6. GCPs from Bing (upper) and TSX (lower) 
By implementing GCP transfer from optical to radar dataset, DEM enhancement can be achieved in order to provide a reliable space borne dataset. In this case, planimetric position of GCPs can be projected onto the Orthorectified Radar Imagery (ORRI) resulted from the first initial orthorectification. Subsequently, these transferred GCPs are used for the improved DEM generation process. This process is continuously running until reach the expected accuracy for 1:10.000 map scale.

The final Ground Sampling Distance (GSD) has been defined in $6 \mathrm{~m}$ for DEM and $1.5 \mathrm{~m}$ for optical satellite imagery. This resolution allows that during digitation, object patterns with optimal zooming can be recognized in stereo plotting environment.

In order to minimize radar data distortion, 3 pairs of both MGD-SE ascending and descending scenes have been involved in the radargrammetric processing. This radargrammetric approach provides DEM in $6 \mathrm{~m}$ resolution which is better than IDEM data (Figure 7).
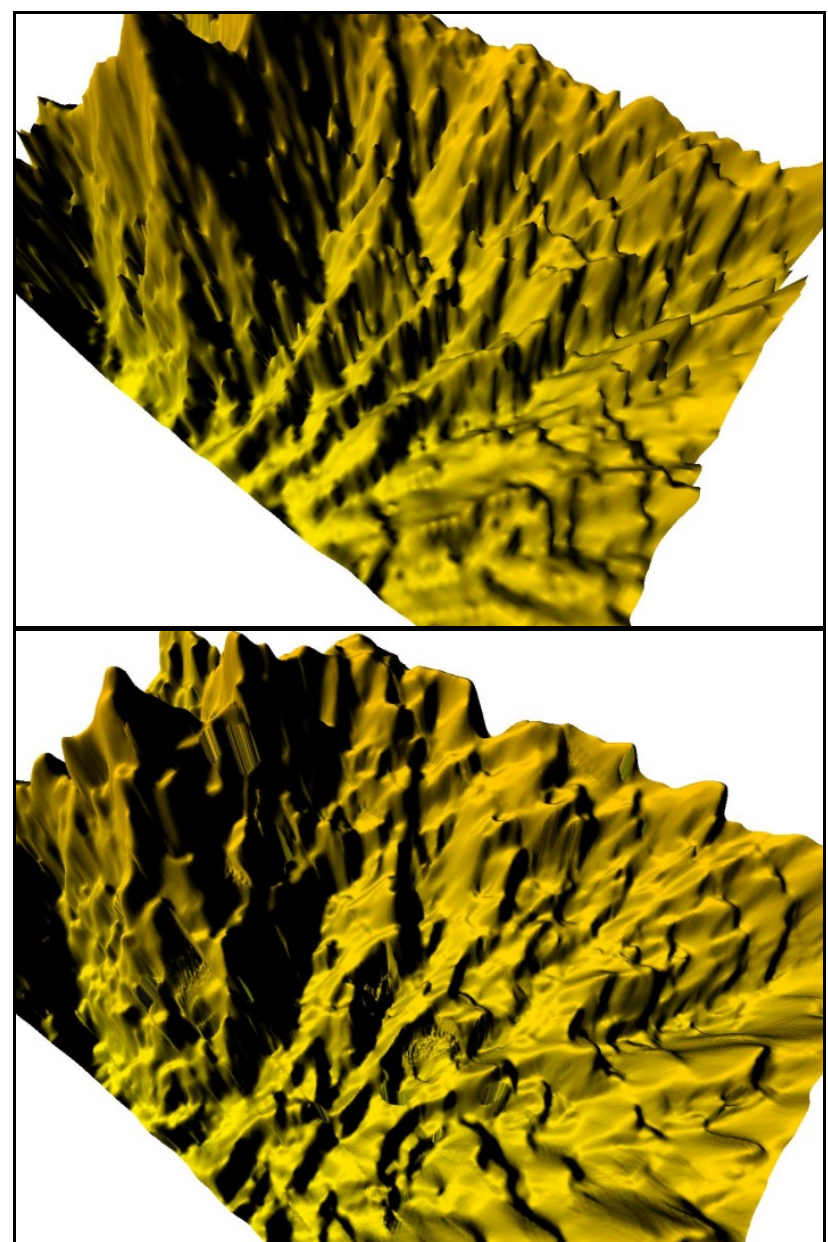

Figure 7. Keramat Hill, Lembang, Bandung: IDEM/12 m GSD (upper) and Improved DEM/6 m GSD (lower)

\subsection{GIS data analysis}

The key role of Geographical Information System (GIS) in this research is mainly related to the vector data production from both orthophotos and DEM. Vector data is the key performance indicator for overall output or end product as it will be used in the subsequent topographical mapping production. The performance will be evaluated based on the correctness and consistency during feature compilation.

Normally in order to achieve better accuracy, topographical features are compiled by using stereo working stations. Based on the official legislation in Indonesia as implemented in the technical specification, there are 8 different themes/layers produced in the topographical mapping:

1. Shoreline/coastal line

2. Hypsography

3. Hydrographic

4. Geographical Names (Toponyms)

5. Administrative Boundary

6. Transportation and Utility

7. Building and Public Facility

8. Land Cover

A further detail accuracy assessment concentrates on the extracted topographical objects i.e. the road network segments. To ensure the geometric accuracy level, stereo compilations for the road objects have been done in order to be encountered as an integral part of DEM components.

\section{ACCURACY ASSESSMENT}

\subsection{Assessment Procedure}

An empirical method has been used as first initial step for obtaining the geometric accuracy level of SPOT-6 data in $1.5 \mathrm{~m}$ resolution. Assuming that GCPs data integration in the orthorectification mechanism will increase the accuracy and minimize some inconsistencies, large scale topographical mapping must be performed properly to achieve geometric accuracy in the scope of National Standard for Spatial Data Accuracy (NSSDA) with $95 \%$ confidence level.

A comprehensive analysis of spatial data accuracy for the corresponding Area of Interest (AOI) has been done by referring to the existing large scale topographic map, which has been derived from air borne campaigns using medium format digital metric camera.

Certainly, the proper topographical map data is required as a valid reference source. Therefore the official large scale topographical map is used as the reference. This 1:5,000 large scale topographical map has been produced in a year of 2012 from airborne data acquisition using medium format digital metric camera. As already demonstrated by (Howard, 1994), in a condition where accurate DEM exists, the statistical error can be computed to calculate geometrical accuracy.

First results show that based on ground survey measurement, it is possible to achieve the required vertical accuracy in the test area. In that sense, it is logical to assume that by only using the GCPs the horizontal accuracy can be increased up to $5 \mathrm{~m}$ horizontal/planimetric accuracy.

\subsection{Geometric Accuracy}

With respect to the geometric accuracy, the National Standard for Spatial Data Accuracy (NSSDA) procedure has been used for geospatial consistency checking (FGDC, 1998). The basic idea behind this method is the detection of blunders from a given data set and the derivation of a statistical model. 
The NSSDA uses Root Mean Square Error (RMSE) to estimate positional accuracy. RMSE is the square root of the average of the set of squared differences between dataset coordinate values and coordinate values from the reference data for identical objects.

The RMSE can be calculated by the following equation (FGDC, 1998) for each corresponding object in the different datasets i.e. between the evaluated data and the reference data. The examination focuses on the point features since the involved spatial data are assumed to be produced with different resolutions and various acquisition methods.

$$
\begin{aligned}
& \operatorname{RMSE}_{X}=\sqrt{\frac{\sum\left(X \mathrm{Re}_{i}-\text { XCheck }_{i}\right)^{2}}{n}} \\
& \text { RMSE }_{Y}=\sqrt{\frac{\sum\left(Y \mathrm{Re}_{i}-\text { YCheck }_{i}\right)^{2}}{n}} \\
& \text { RMSE }_{r}=\sqrt{\text { RMSE }_{X}^{2}+\text { RMSE }_{Y}^{2}} \\
& \text { Accuracy }_{r}=1.7308 \times \text { RMSE }_{r} \\
& \text { RMSE }_{Z}={ }_{r} \sqrt{\frac{\sum\left(Z \mathrm{Re}_{i}-\text { ZCheck }_{i}\right)^{2}}{n}} \\
& \text { Accuracy }_{Z}=1.96 \times \text { RMSE }_{Z}
\end{aligned}
$$

where:

RMSE $_{\mathrm{x}}=$ Root Mean Square Error in $\mathrm{x}$ axis direction $\mathrm{RMSE}_{\mathrm{y}}=$ Root Mean Square Error in y axis direction RMSE $_{\mathrm{r}}=$ Horizontal (2D) Root Mean Square Error $\mathrm{RMSE}_{\mathrm{Z}}=$ Vertical (3D) Root Mean Square Error $\left(\mathrm{XRe}_{\mathrm{i}}, \mathrm{YRe}_{\mathrm{i}}, \mathrm{ZRe}_{\mathrm{i}}\right)=$ Coordinates of check-points $\mathrm{i}$ in the reference dataset

$\left(\right.$ XCheck $_{\mathrm{i}}$, YCheck $\left._{\mathrm{i}}, \mathrm{ZCheck}_{\mathrm{i}}\right)=$ Coordinates of check-points i in the evaluated dataset

$\mathrm{n}=$ number of check-points

The accuracy is given in ground distances at the 95\% confidence level. It means that $95 \%$ of the positions in the dataset will have an error with respect to true ground position that is equal to or smaller than the reported accuracy value. The reported accuracy value reflects all uncertainties, including those introduced by geodetic control coordinates, compilation, and final computation of ground coordinate values in the end product (Figure 8).

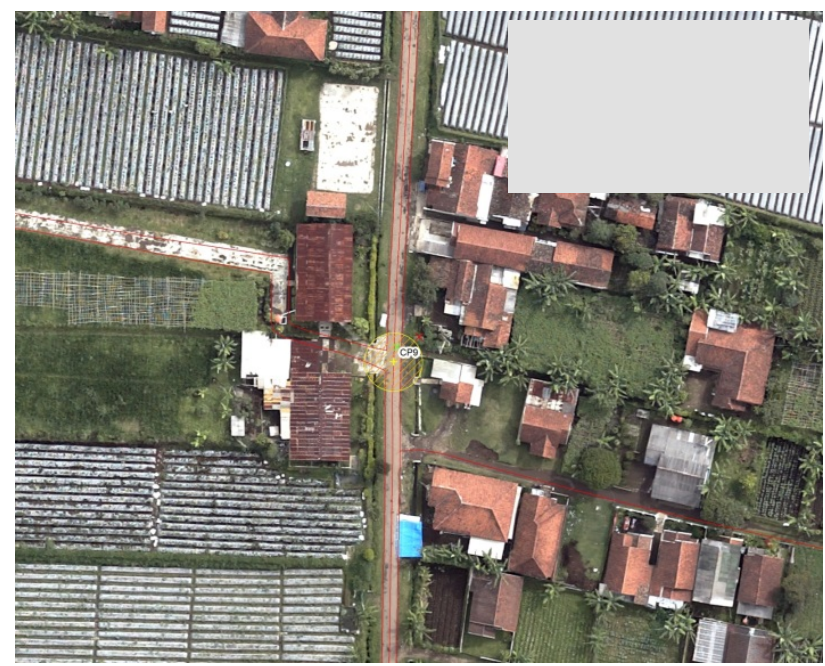

Figure 8. Planimetric Accuracy
Based on the Indonesian National Mapping Accuracy Standard (NMAS), the horizontal tolerance accuracy can be seen in Table 5. Differently to NSSDA accuracy, NMAS introduced a circular error in $90 \%$ level of confidence which is more moderate than NSSDA in what so called Circular Map Accuracy (CMAS) as put in Eq. 7.

$$
\text { CMAS }_{r}=1.5175 * R M S E_{r}
$$

\begin{tabular}{|c|c|c|}
\hline $\begin{array}{c}\text { Map } \\
\text { Scale }\end{array}$ & $\begin{array}{c}\text { Tolerance at } \\
\text { Publication Scale }\end{array}$ & $\begin{array}{c}\text { Tolerance at } \\
\text { Ground Distance }\end{array}$ \\
\hline $1: 1,000$ & $1 / 30$ inch $=0.85 \mathrm{~mm}$ & $0.850 \mathrm{~m}$ \\
\hline $1: 2,500$ & $1 / 30$ inch $=0.85 \mathrm{~mm}$ & $2.125 \mathrm{~m}$ \\
\hline $1: 5,000$ & $1 / 30$ inch $=0.85 \mathrm{~mm}$ & $4.250 \mathrm{~m}$ \\
\hline $1: 10,000$ & $1 / 30$ inch $=0.85 \mathrm{~mm}$ & $8.500 \mathrm{~m}$ \\
\hline $1: 25,000$ & $1 / 50$ inch $=0.5 \mathrm{~mm}$ & $12.500 \mathrm{~m}$ \\
\hline $1: 50,000$ & $1 / 50$ inch $=0.5 \mathrm{~mm}$ & $25.000 \mathrm{~m}$ \\
\hline
\end{tabular}

Table 5. NMAS Horizontal Accuracy Tolerance

National Mapping Accuracy Standard (NMAS) defines an absolute Horizontal (circular error) and a vertical (linear error) at $90 \%$ level of confidence. In terms of elevation data for 1:10,000 topographical mapping, it means that $90 \%$ of spot elevations must be within $8.5 \mathrm{~m}$ of their true horizontal position and $90 \%$ measured vertical elevation shall be within $2.5 \mathrm{~m}$ (half of the contour interval) of the absolute height.

\begin{tabular}{|l|r|r|r|r|}
\hline \multirow{2}{*}{} & \multicolumn{2}{|c|}{ Ortho on Space $(\mathrm{m})$} & \multicolumn{2}{c|}{ Ortho by GCP (m) } \\
\cline { 2 - 5 } & AOI & $1: 5,000$ & AOI & $1: 5,000$ \\
\hline $\begin{array}{l}\text { NSSDA } \\
(95 \%)\end{array}$ & 6.467 & 8.150 & 4.695 & 4.368 \\
\hline $\begin{array}{l}\text { NMAS } \\
(90 \%)\end{array}$ & 5.760 & 7.259 & 4.182 & 3.890 \\
\hline
\end{tabular}

Table 6. Planimetric accuracy of SPOT6 data

This paper has identified absolute planimetric accuracy of the final orthorectified SPOT 6 data by evaluation of general (AOI) and specific test area in 1:5,000 map sheet (Table 6). There are 19 ICPs selected from the road and building dataset.

\begin{tabular}{|l|c|r|r|c|}
\hline & $\begin{array}{c}\text { IDEM } \\
(\mathrm{m})\end{array}$ & $\begin{array}{c}\text { ASTER } \\
\text { GDEM (m) }\end{array}$ & $\begin{array}{c}\text { Improved } \\
\text { DEM (m) }\end{array}$ & $\begin{array}{c}\text { Bing } \\
(\mathrm{m})\end{array}$ \\
\hline $\begin{array}{l}\text { NSSDA } \\
(95 \%)\end{array}$ & 4.273 & 12.410 & 3.451 & 132.212 \\
\hline $\begin{array}{l}\text { NMAS } \\
(90 \%)\end{array}$ & 3.745 & 10.880 & 3.025 & 115.919 \\
\hline
\end{tabular}

Table 7. DEM Vertical accuracy

Based on height deviation from road network features in 1:5.000 topographical map, the RMSE $\mathrm{z}_{\mathrm{z}}$ can be calculated using Eq.7 (Table 7). For this purpose, 8,391 vertices (3D points) has been extracted as road segment components which are used in the accuracy assessment (Figure 9). 


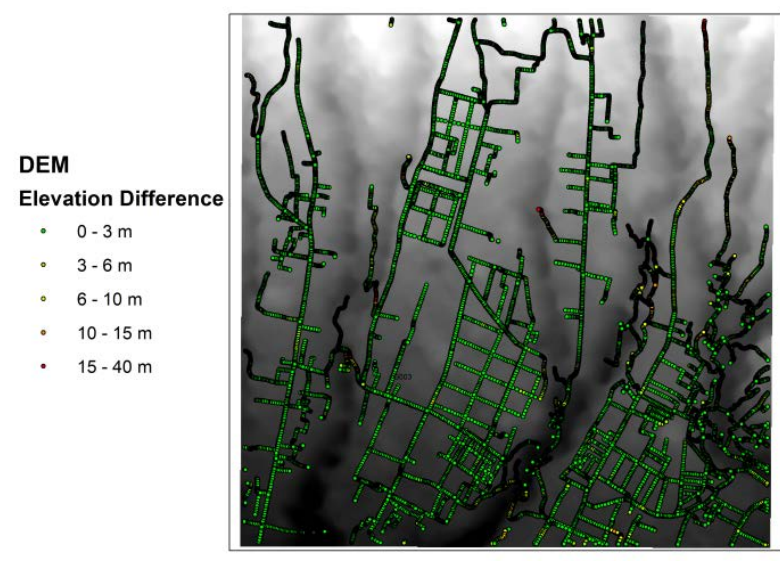

Figure 9. Height accuracy of improved DEM

Inaccurate height calibration in GCPs gives more significant geometric deviation in Bing. Radargrammetric process using GCP from Bing estimates height from ASTER GDEM which propagates error from 12.410 to $132.212 \mathrm{~m}$ (Table 7). It is also confirmed by the unbalanced ratio between planimetric and vertical accuracies.

\section{CONCLUSIONS}

Topographic maps with absolute NSSDA (95\%) of $5 \mathrm{~m}$ (accuracy) can be produced by iterative orthorectification of SPOT-6 data with 33 full control GCPs for 60 x $60 \mathrm{~km}$ AOI. It provides relatively inexpensive measures in order to generate orthoimages sufficient enough for 1:10,000 Large Scale Topographical Mapping requirements in Indonesia.

This research has shown the significant geometrical improvement of DEM generation by implementing integration mechanism between optic and radar space borne data in which appropriate for 1:10.000 planimetric accuracy. However for the DEM quality, it is still necessary to improve the output in order to fulfil 1:10,000 topographic mapping requirements.

\section{ACKNOWLEDGEMENTS}

We would like to acknowledge Geospatial Information Agency of Indonesia (BIG) for providing full access to the topographical maps, GPS raw data of reference station (CORS) during the campaign and necessary processing software licenses (PCI Geomatics). In addition, we would like to thank both Airbus Defence and Space (Astrium) and German Aerospace Agency (DLR) for providing TerraSAR-X/TanDEM-X data under the scientific proposal IDEM_CALVAL0019.

\section{REFERENCES}

Breit, Helko, et al., 2012. Bistatic and interferometric processing of TanDEM-X data. In: EUSAR. 9th European Conference on Synthetic Aperture Radar.

DLR, 2013. TanDEM-X Ground Segment DEM Products Specification Document (version 3.0), Oberpfaffenhofen, Germany, TD-GS-PS-0021, pp.11-13.

FGDC, 1998. Geospatial Positioning Accuracy Standards Part 3: National Standard for Spatial Data Accuracy (version 2.0), Washington, D.C., FGDC-STD-001-1998: Federal Geographic Data Committee, pp.3-4.
Howard. A., 1994. Accuracy of Topographic Maps Derived from ERS-1 Interferometric Radar. IEEE Transaction on Geoscience and Remote Sensing Vol. 32, No.4, pp.823-836.

Schneiderhan, Tobias, et al., 2010. Insights to the Emergency Mapping Service within the GMES project SAFER Highlights, main achievements and challenges. In: Living Planet Symposium, Bergen, Norway.

Tampubolon, W., Hendrayana, E., 2012. Orthorectification of Very High Resolution Satellite Imagery in the context of detail spatial planning purposes. In: International Conference of Applied Geoinformatics for Society and Environment (AGSE), Johor Bahru, Malaysia http://www.appliedgeoinformatics.org/downloads/AGSE2012_2nd_edition_2012_ 08_17.pdf (28 Jan. 2015).

USGS, 1993. Data User Guide, Digital Elevation Models, Virginia,USA,http://agdc.usgs.gov/data/usgs/geodata/dem/dugd em.pdf (28 Jan.2015). 